\title{
DIMBOA levels in hexaploid Brazilian wheat are not associated with antibiosis against the cereal aphids Rhopalosiphum padi and Sitobion avenae
}

\author{
Jorge F. Pereira • André L. F. Sarria - Stephen J. Powers • Gudbjorg I. Aradottir • \\ John C. Caulfield · Janet Martin • Lesley E. Smart • John A. Pickett • \\ Michael A. Birkett • Paulo R. V. S. Pereira
}

Received: 4 November 2016/Accepted: 11 May 2017/Published online: 25 May 2017

(C) Brazilian Society of Plant Physiology 2017

\begin{abstract}
The objective of this study was to evaluate the natural levels of the plant defence compound DIMBOA (2,4-dihydroxy-7-methoxy-1,4-benzoxazin-3-one) in young leaves of eight hexaploid Brazilian wheat genotypes and the impact of the genotypes upon development of cereal aphids, Rhopalosiphum padi and Sitobion avenae. HPLC analysis revealed that the DIMBOA levels varied from 5.376 (in BRS Guabiju) to $30.651 \mathrm{mmol} \mathrm{kg} \mathrm{FW}^{-1}$ (in BRS Timbaúva) with two genotypes outperforming Solstice, a
\end{abstract}

Electronic supplementary material The online version of this article (doi:10.1007/s40626-017-0084-z) contains supplementary material, which is available to authorized users.

J. F. Pereira $(\square)$ · P. R. V. S. Pereira

Embrapa Trigo, Rodovia BR 285, km 294, Passo Fundo, RS 99001-970, Brazil

e-mail: jorge.pereira@embrapa.br

Present Address:

J. F. Pereira

Embrapa Gado de Leite, Rua Eugênio do Nascimento 610, Juiz de Fora, MG 36038-330, Brazil

A. L. F. Sarria - G. I. Aradottir · J. C. Caulfield . J. Martin - L. E. Smart - J. A. Pickett - M. A. Birkett Biological Chemistry and Crop Protection Department, Rothamsted Research, West Common, Harpenden, Hertfordshire AL5 2JQ, UK

\section{S. J. Powers}

Computational and Systems Biology Department, Rothamsted Research, West Common, Harpenden, Hertfordshire AL5 2JQ, UK
UK variety used as reference. Bioassays were conducted to evaluate the development and fecundity of both aphids when grown on the wheat genotypes. Although BRS Guabiju and BRS Timbaúva were among the genotypes showing the highest susceptibility and resistance, respectively, against both aphid species, no correlation could be found between DIMBOA levels and antibiosis effects. The cultivar BRS 327 was among the genotypes showing lower intrinsic rate of population increase for the two aphid species. Elucidating the role of secondary metabolites in plant resistance to aphids and the characterization of the genotypes that allowed reduced development of $R$. padi and $S$. avenae are important steps to achieve a better natural resistance in hexaploid Brazilian wheat.

Keywords Aphid development - HPLC . Hydroxamic acids $\cdot$ Plant resistance $\cdot$ Triticum aestivum

\section{Introduction}

Aphids (Homoptera:Aphididae) affect global wheat production through their direct and indirect effect upon plant performance, including reduction of plant resources and plant virus transmission (Züst and Agrawal 2016). Various aphid species infest wheat, including the bird cherry-oat aphid, Rhopalosiphum padi (Linnaeus), and the English grain aphid, Sitobion 
avenae (Fabricius), the two most economically important aphid species in Brazil. Rhopalosiphum padi is the most frequent species found in Brazilian wheat fields, especially in winter, followed by $S$. avenae, which is commonly observed during wheat heading stage. Rhopalosiphum padi is relatively stable in abundance over the year, indicating a good adaptation of this species to the conditions of South Brazil (Lau et al. 2009). Rhopalosiphum padi is also the most efficient $\mathrm{B} / \mathrm{CYDV}$ s vector in south Brazil and BYDV-PAV is the predominant virus in winter cereals in that region (Parizoto et al. 2013). Yield losses caused by BYDV in Brazilian commercial cultivars ranged from 40 to $50 \%$ when wheat was infected in early developmental stages (Lau et al. 2015).

Controlling aphids with insecticides in the south of Brazil is necessary (Pereira et al. 2010). The disadvantages of this type of control are undesirable effects for the environment and human health, high production costs and rise of insecticide resistance. For instance, up to date, 602 arthropod species have shown resistance to at least one pesticide (Whalon et al. 2017) and, in 2015, the global market for synthetic pesticides, which account for near 30\% of the pesticides used worldwide (Grube et al. 2011), was evaluated at $\$ 54.8$ billion (BCC Research 2017). That market is forecast to grow at a compound annual growth rate of $4.8 \%$ from 2016 to 2021 increasing its value to $\$ 71.0$ billion by 2021 (BCC Research 2017). In order to reduce dependency upon insecticides and thus provide affordable and sustainable solutions for wheat farmers, the search for natural plant resistance against aphids is important. One way to explore the natural resistance in wheat against aphids could be to explore plant secondary metabolites that can play an important role affecting aphid behavior. Hydroxamic acids (also known as benzoxazinoids) are among the metabolites that show detrimental effects against aphids (Züst and Agrawal 2016). These acids appear to affect aphid feeding and reproduction, to reduce BYDV transmission and, in some cases, their concentration has a positive correlation with wheat resistance against different aphid species (Niemeyer 2009). Younger plants show higher levels of hydroxamic acids although they can be detected in different tissues of older cereal plants, being found mainly as the inactive glucoside (Niemeyer 2009; Makowska et al. 2015; Züst and Agrawal 2016). The glucosylated hydroxamic acids are stored in the vacuole, and upon tissue injury, are cleaved by $\beta$-glucosidases from plastids, which releases the biologically active aglycones. Different types of hydroxamic acids (HDMBOA, HMBOA, MBOA, MBOA- $N$-Glc, BOA and TRIMBOA-Glc) can be found in plants (Niemeyer 2009) and different levels of toxicity are reported for these molecules (Meihls et al. 2013). In wheat, DIMBOA (2,4-dihydroxy-7-methoxy-1,4-benzoxazin-3-one) is the main hydroxamic acid isolated (Meihls et al. 2013; Maag et al. 2014; Makowska et al. 2015; Handrick et al. 2016; Wouters et al. 2016). DIMBOA has been shown to have a toxic effect against aphids when applied in artificial diets (Elek et al. 2013a) and it has also been shown to induce callose deposition as a plant defense response (Ahmad et al. 2011; Meihls et al. 2013). Thus, hydroxamic acids are an interesting target for their potential to confer natural resistance against aphids. In wheat, specific cultivars could then be used to give a low cost approach to aphid control, thus reducing economic losses caused by aphids/BYDV and also the use of insecticides in agriculture.

The assessment of wheat plant resistance against aphids can be evaluated by different characteristics such as antixenosis (negative effect on the insect acceptance), antibiosis (negative effect on the insect physiology), and tolerance (ability to cope with the attack by the insects whilst sustaining only a small reduction in some characteristic-yield, for instance). For a specific cultivar, one of these characteristics can be more important than the other (Cao et al. 2015). Some Brazilian wheat genotypes have been evaluated for tolerance to $R$. padi and/or BYDV and for antixenosis and antibiosis to $S$. avenae (Lanzarini et al. 2007; Peruzzo et al. 2007; Cezare et al. 2011; Savaris et al. 2013; Silva et al. 2013). Although the methodologies employed in these studies were different from each other, in general, the cultivar BRS Timbaúva is described as resistant (based on antibiosis and tolerance studies) to $R$. padi and potentially tolerant to BYDV but, on the other hand, it appears to be sensitive (by antibiosis) to $S$. avenae. On the other hand, BRS Guabiju is sensitive (based on antibiosis and tolerance studies) to $R$. padi. Clearly, there is a variation in aphid resistance among Brazilian wheat genotypes but, up to now, the biochemical and physiological basis of this resistance has not been investigated. This work investigated the abundance of the hydroxamic acid DIMBOA in young leaf tissue of 
Brazilian wheat cultivars and considered whether DIMBOA concentration correlated with antibiosis effects on $R$. padi and $S$. avenae development.

\section{Materials and methods}

\subsection{Aphids}

Rhopalosiphum padi and S. avenae were collected in the field and were identified in the laboratory prior to experimentation. The wheat variety Tybalt and the barley variety Saffron were then used to establish laboratory colonies from one single aphid of $S$. avenae or $R$. padi, respectively. Colonies and plants were maintained in a growth chamber at $20{ }^{\circ} \mathrm{C}$ and light regime 16:8 L:D. New colonies were set up every week, and the alates were collected from 4 to 5 weekold colonies.

\subsection{Wheat genotypes}

Eight hexaploid Brazilian wheat genotypes (BR 32, BRS 327, BRS 328, BRS Guabiju, BRS Guamirim, BRS Parrudo, PF869120 and BRS Timbaúva) were chosen for evaluation along with one UK variety (Solstice). BRS Guabiju and BRS Timbaúva were chosen due to their difference in resistance to $R$. padi based on antibiosis and tolerance studies (Peruzzo et al. 2007; Savaris et al. 2013). BR 32 and PF 869120 are the parents of BRS Timbaúva, and BRS 327, BRS 328, BRS Guamirim and BRS Parrudo are among the modern wheat cultivars released by Embrapa Trigo (year of release from 2005 to 2012). Seeds of the Brazilian genotypes were provided by the Embrapa Active Wheat Germplasm Bank. Solstice seeds were provided by RAGT Seeds Ltd., Cambridge, UK.

\subsection{Extract preparation}

Wheat seeds were sown in trays $(5 \times 8$ wells per tray) containing Rothamsted standard compost mix, incubated in a growth chamber $\left(22^{\circ} \mathrm{C}, 16: 8 \mathrm{~L}: \mathrm{D}\right)$ and arranged in a completely randomised design. Subsequently, leaf tissue was collected at 7,9 and 14 days after sowing. On each day of analysis, the plants were transported to the laboratory where the middle part of the leaf was removed from 6 to 10 plants, depending on the size of the plants, and 3-8 biological replicates were performed for each genotype. The leaf tissue was frozen in liquid nitrogen, ground with a mortar and pestle, transferred to a $2 \mathrm{~mL}$ Eppendorf tube (containing two metal beads). The weight of each sample was recorded and used later to calculate the volume of buffer to be added and the DIMBOA concentration. For further trituration of the leaf tissue, another two metal beads were added at the top of the sample and the tubes were then placed in a TissueLyser (Qiagen) for $4 \mathrm{~min}$ and frequency of $30 \mathrm{~s}^{-1}$. After that, extraction buffer containing 98\% methanol (Fisher Scientific, UK) and $2 \%$ acetic acid ( $\geq 99 \%$, SigmaAldrich, UK) was added using the proportion of $1 \mathrm{~mL}$ to every $500 \mathrm{mg}$ of tissue. Samples were vortexed and incubated at room temperature for $5 \mathrm{~min}$. To separate the debris from the buffer, the samples were centrifuged twice at $4{ }^{\circ} \mathrm{C}$ for $10 \mathrm{~min}$ and $16,100 \times g$ and the buffer was then completely evaporated under nitrogen flow. Samples were re-suspended in $200 \mu \mathrm{L}$ of the buffer, centrifuged again and transferred into glass vials. After analysis by HPLC, the samples were stored at $-80{ }^{\circ} \mathrm{C}$.

\subsection{High pressure liquid chromatography (HPLC)}

The method used here was adapted from Baumeler et al. (2000). An ACE C-18 column (dimension $250 \times 4.6 \mathrm{~mm}$, particle size $5 \mu \mathrm{m}$, pore size $100 \AA$ ) was used in a DGU-20A5 Prominence Degasser (Shimadzu) and the mobile phase involved deionized water plus $0.025 \%$ acetic acid (solvent A) and methanol/isopropanol (95/5) (isopropanol $\geq 99.8 \%$, Sigma-Aldrich, UK) plus acetic acid $0.025 \%$ (solvent $\mathrm{B})$ in the gradient mode: $0-15 \mathrm{~min}, 10 \% \mathrm{~B}$; 15-45 min, 40\% B; 45-55 min, 75\% B; 55-62 min, $95 \% \mathrm{~B}$; and $62-65 \mathrm{~min}, 10 \% \mathrm{~B}$. The injection volume was $10 \mu \mathrm{L}$ with a flow rate of $1 \mathrm{~mL} \mathrm{~min}^{-1}$ and run time of $65 \mathrm{~min}$. The absorbance was monitored at $254 \mathrm{~nm}$.

\subsection{DIMBOA quantification}

DIMBOA (800 mg, $>94 \%$ purity) was synthesized in four steps starting from commercially available 3-methoxyphenol (96\%, Sigma-Aldrich, UK) and a calibration curve was constructed for determination of its concentration in wheat cultivars. A primary stock standard solution of DIMBOA at a concentration of $1000 \mu \mathrm{g} \mathrm{mL}^{-1}$ was prepared using methanol as 
solvent, and diluted to produce nine different concentrations of DIMBOA $(250,175,100,75,50,30,20,10$ and $5 \mu \mathrm{g} \mathrm{mL}^{-1}$ ). Each final concentration was tested in triplicate. Ten $\mu \mathrm{L}$ of each solution was injected and analysed by HPLC using the method described above. Linear regression analysis was used to relate the area under HPLC peaks to the known concentration of DIMBOA used in the calibration. The fitted line allowed the quantity of DIMBOA in the wheat leaf samples to be estimated, having rearranged the equation of the fitted model to be in terms of concentration of DIMBOA for a given area (Supplementary Fig. 1). The unequal numbers of replicates for the combinations of genotype by time (days) precluded application of analysis of variance (ANOVA) so the method of residual maximum likelihood (REML) was used to fit a linear mixed model to the concentration (of DIMBOA) data. This allowed the testing (approximate F-tests) of the main effects and the interaction between the factors of genotype and time followed by the comparison of means of interest using the standard error of the difference (SED) between means on the appropriate degrees of freedom, thus invoking the least significant difference (LSD) at the 5\% level of significance. A natural $\log$ transformation was required to account for heterogeneity of variance over the combinations of genotype and time. The GenStat (17th edition, VSN International Ltd, Hemel Hempstead, UK) statistical package was used for these analyses.

\subsection{Nuclear magnetic resonance (NMR) spectroscopy}

1D ${ }^{1} \mathrm{H}$ NMR, ${ }^{13} \mathrm{C}$ NMR and 2D (COSY, HSBC, HMBC) spectra (Supplementary Figs. 2-13) were acquired on a Bruker Avance spectrometer operating at $500 \mathrm{MHz}$ for ${ }^{1} \mathrm{H}$ and $125 \mathrm{MHz}$ for ${ }^{13} \mathrm{C}$, equipped with a $5 \mathrm{~mm}$ broad band probe (BBO), using $\mathrm{CD}_{3} \mathrm{OD}$ (deuterated methanol 99.9\%, Goss Scientific, UK) as solvent $(2.0 \mathrm{mg}$ of sample was dissolved in $0.5 \mathrm{~mL}$ of solvent and transferred into a $5 \mathrm{~mm}$ NMR tube). The ${ }^{1} \mathrm{H}$ and ${ }^{13} \mathrm{C}$ NMR spectra were collected, respectively with free induction decays (FID). The two-dimensional (2D) experiments were acquired and processed with software provided by Bruker. Standard pulse sequences were used for $1 \mathrm{H}-1 \mathrm{H} \mathrm{COSY} 90^{\circ}$. Two dimensional inverse hydrogen detected heteronuclear shift correlation HSQC spectra were obtained with software provided by Bruker (TopSpin). Two-dimensional inverse hydrogen detected heteronuclear long range correlation ${ }^{1} \mathrm{H}-{ }^{13} \mathrm{C}$ HMBC experiments were carried out using also the software provided by Bruker. 2,4-Dihydroxy-7methoxy-1,4-benzoxazin-3-one (DIMBOA): ${ }^{1} \mathrm{H}$ NMR $\left(\mathrm{CD}_{3} \mathrm{OD}, 500 \mathrm{MHz}\right): \delta_{\mathrm{H}} 7.26(1 \mathrm{H}, \mathrm{d}, J=10.0 \mathrm{~Hz}$, H5), 6.68 (1H, dd, $J=5.0,10.0 \mathrm{~Hz}, \mathrm{H} 6), 6.63(1 \mathrm{H}, \mathrm{d}$, $J=5.0 \mathrm{~Hz}, \mathrm{H} 8), 5.67(1 \mathrm{H}, \mathrm{s}, \mathrm{H} 2), 3.77\left(3 \mathrm{H}, \mathrm{s}, \mathrm{OCH}_{3}\right)$, ${ }^{13} \mathrm{C} \mathrm{NMR}\left(\mathrm{CD}_{3} \mathrm{OD}, 125 \mathrm{MHz}\right): \delta_{\mathrm{c}} 159.9,159.2,144.9$, 122.0, 115.7, 109.4, 105.3, 94.5, 56.6. 2-O- $\beta$-D-glucopyranosyl-4-hydroxy-7-methoxy-1,4-benzoxazin-3one (DIMBOA-Glc): ${ }^{1} \mathrm{H}$ NMR $\left(\mathrm{CD}_{3} \mathrm{OD}, 500 \mathrm{MHz}\right): \delta_{\mathrm{H}}$ $7.26(1 \mathrm{H}, \mathrm{d}, J=10.0 \mathrm{~Hz}, \mathrm{H} 5), 6.70(1 \mathrm{H}, \mathrm{dd}, J=4.5$, $10.0 \mathrm{~Hz}, \mathrm{H} 6), 6.75(1 \mathrm{H}, \mathrm{d}, J=5.0 \mathrm{~Hz}, \mathrm{H} 8), 5.91(1 \mathrm{H}, \mathrm{s}$, $\mathrm{H} 2), 4.67\left(1 \mathrm{H}, \mathrm{d}, J=10.0 \mathrm{~Hz}, \mathrm{H}^{\prime}\right), 3.78(3 \mathrm{H}, \mathrm{s}$, $\left.\mathrm{OCH}_{3}\right), 3.87\left(1 \mathrm{H}, \mathrm{dd}, J=4.5,10.0 \mathrm{~Hz}, \mathrm{H}^{\prime}{ }_{\mathrm{eq}}\right), 3.68$ $\left(1 \mathrm{H}, \mathrm{dd}, J=5.0,15.0 \mathrm{~Hz}, \mathrm{H}^{\prime}{ }_{\mathrm{ax}}\right), 3.18\left(1 \mathrm{H}, \mathrm{m}, \mathrm{H}^{\prime}\right)$, $3.34\left(1 \mathrm{H}, \mathrm{d}, \quad J=10.0 \mathrm{~Hz}, \mathrm{H} 5^{\prime}\right), 3.29(1 \mathrm{H}, \mathrm{d}$, $\left.J=10.0 \mathrm{~Hz}, \mathrm{H} 3^{\prime}\right), 3.30\left(1 \mathrm{H}, \mathrm{m}, \mathrm{H} 4^{\prime}\right),{ }^{13} \mathrm{C} \mathrm{NMR}$ $\left(\mathrm{CD}_{3} \mathrm{OD}, 125 \mathrm{MHz}\right), \delta_{\mathrm{c}} 160.7,157.2 ; 142.1 ; 122.1$; 115.2; 110.0 ; 105.4; 104.4; 98.4; 78.5; 77.9; 75.4; 71.9; $63.3 ; 56.8$.

\subsection{Liquid chromatography-mass spectrometry (LC-MS) and NMR analysis}

LC-MS/MS analysis was performed using a Micromass Quattro Ultima, high performance bench-top triple quadrupole mass spectrometer, designed for routine LC-MS/MS operation, hyphenated to a Waters Acquity UPLC system (Ultra Performance Liquid Chromatography). MS analysis was undertaken using negative ion electrospray conditions, with a capillary voltage of $2.7 \mathrm{kV}$, cone voltage $30 \mathrm{~V}$, mass range $50-1000 \mathrm{~m} \mathrm{z}^{-1}$. The source temperature was $130{ }^{\circ} \mathrm{C}$, desolvation temperature $350{ }^{\circ} \mathrm{C}$, desolvation gas flow $1000 \mathrm{~L} \mathrm{~h}^{-1}$ (nitrogen) and cone gas flow $60 \mathrm{~L} \mathrm{~h}^{-1}$ (nitrogen). Samples $(1 \mu \mathrm{L})$ were injected via the Acquity sample manager, onto an Acquity UPLC BEC C18 $1.7 \mu \mathrm{m}$ $2.1 \times 150 \mathrm{~mm}$ column. The run time was $40 \mathrm{~min}$ at a flow rate of $0.21 \mathrm{~mL} \mathrm{~min}^{-1}$. Solvents used were water: formic acid (Solvent A) and methanol (Solvent B) in the gradient mode: 0-8.7 min, $10 \% \mathrm{~B} ; 8.7-26.7 \mathrm{~min}, 70 \%$ B; 26.7-32.7 min, 75\% B; 32.7-36.9 min, 95\% B and 36.7-38.7 min, $10 \%$ B. Selected ions were admitted to the collision cell for MS/MS analysis with argon admitted at a pressure of $2.1 \mathrm{e}^{-3}$ mbar, causing CID. Fragment ions were detected in the second quadrupole (Supplementary Fig. 14). 


\subsection{Aphid development assays}

Bioassays were conducted to investigate the effects of Brazilian wheat genotypes against the development and fecundity of $S$. avenae and $R$. padi. Alate aphids from the top of the rearing cage were collected using an electric pooter. The bioassays were conducted using aphids that were collected together and randomly allocated inside $2 \mathrm{~cm}$ diameter clip cages. Four alate $R$. padi or six alate $S$. avenae were transferred to one cage that was placed in the middle part of the first leaf of the 7 days old plant, with growth conditions as described above. For each genotype 12-16 cages (plants) were used, and the experiments (one for each aphid species) were repeated twice in a growth chamber at $22{ }^{\circ} \mathrm{C}$ with 16:8 L:D. Different development measurements were evaluated in each experiment as follows:

(i) Nymph production by adult alate aphid. Alate adults were left for $24 \mathrm{~h}$ in the cages. After this time, adults were removed and the number of nymphs produced in each cage was counted;

(ii) Weight development evaluation. The nymphs produced after $24 \mathrm{~h}$ were left in the cages to develop. After 6 days, the nymphs were removed from the cages, counted and weighted. The average nymph weight was used to calculate the mean growth rate (MGR), as this average weight (measured on the sixth day) divided by six;

(iii) Intrinsic rate of population increase $\left(r_{m}\right)$. After the weight measurements had been taken, one randomly selected aphid was put back in each cage and monitored at the same time each day. The time to produce the first nymph was recorded. Every day the number of nymphs was recorded and the nymphs were removed. The $r_{m}$ was calculated by the formula published by Wyatt and White (1977):

$$
r m=\frac{c(\log e M d)}{d}
$$

where $c$ is a constant (0.74), $d$ is the time to produce the first nymph and $M d$ is the number of nymphs produced over a period equivalent to $d$.

The mean number of nymphs per adult alate, the mean growth rate (MGR) (over six days) and the intrinsic rate of population increase $\left(r_{m}\right)$ were also analysed using a linear mixed model. In this case, a random effects term for experiments and cages nested within experiments were included, so that variation due to these was accounted for prior to testing for the differences between genotypes. No transformation of the data was required in this case. The Pearson correlation between the means of the three responses with the concentrations of DIMBOA at 7,9 and 14 days for the nine genotypes was considered and tested for significance using the F-test.

\section{Results}

\subsection{Levels of DIMBOA in Brazilian wheat genotypes}

The extraction and separation methods used here were efficient in detecting DIMBOA in 7, 9 and 14 day-old leaves from all Brazilian genotypes and Solstice (Fig. 1). The mean concentration of DIMBOA (mmol per $\mathrm{kg}$ leaf tissue), which was calculated using an external calibration curve (Supplementary Fig. 1), was variable among the genotypes and the time points analysed (Fig. 1a). In 7 day-old leaves, the highest levels of DIMBOA were identified in BRS Timbaúva (30.651 mmol kg FW ${ }^{-1}$ ), which originated from the cross between BR 32 and PF869120, and BRS Guamirim $\left(27.428 \mathrm{mmol} \mathrm{kg} \mathrm{FW}^{-1}\right)$ which were not significantly different $(P<0.05, \mathrm{LSD})$. The lowest level was in BRS Guabiju (5.376 mmol kg FW ${ }^{-1}$ ). There was a highly significant interaction between genotype and time $(P<0.001$, F-test $)$ (Table S1). For all genotypes, the amount of DIMBOA was higher in 7 day-old leaves and was reduced when leaves were 9 and 14 days old except for BRS Parrudo (Fig. 1a), which had its highest DIMBOA level in 9 day-old leaves. The difference between the greatest and lowest DIMBOA level was lowest at 9 and 14 days. BRS Guabiju also showed the lowest level at 14 days though was not significantly different $(P<0.05$, LSD) from BR 32. Using the level of DIMBOA from Solstice as $100 \%$, it is clear that the Brazilian wheat genotypes presented a large variation in DIMBOA concentration (Fig. 1b), with levels varying from 39.931 to $227.647 \%$ of that in Solstice at the 7 th day, from 14.775 to $174.614 \%$ at the 9 th day and from 19.245 to $155.373 \%$ at the 14 th day. Genotypes 

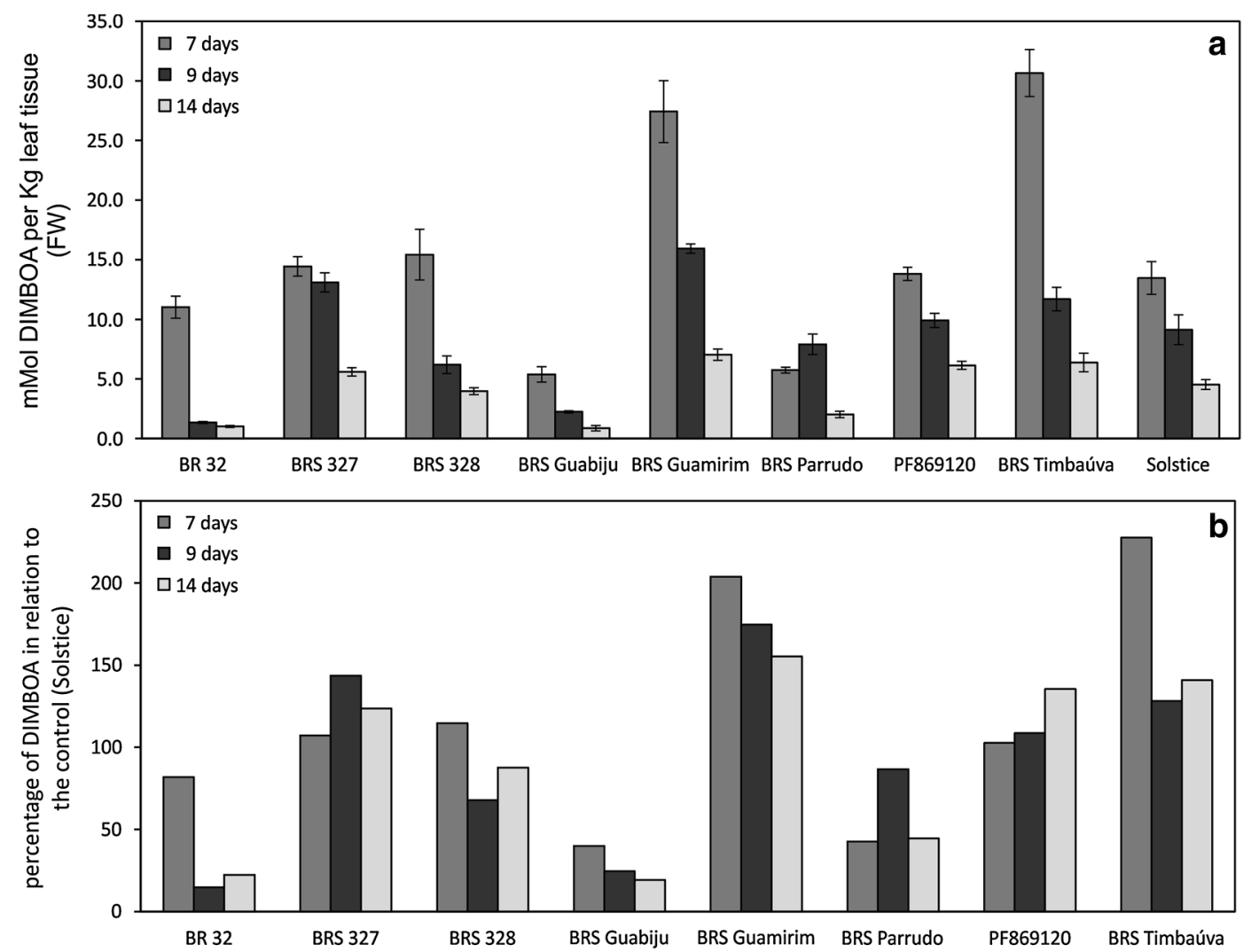

Fig. 1 DIMBOA levels in 7, 9, and 14 days old leaf tissue of the tested genotypes. a Concentration in mol of DIMBOA per $\mathrm{kg}$ of leaf fresh weight $(\mathrm{FW})$ and $\mathbf{b}$ relative DIMBOA concentration

showing the highest level of DIMBOA at day 14th were BRS Guamirim, BRS Timbaúva, PF869120 and BRS 327 (not significantly different from each other, $P<0.05$, LSD). The lowest decrease in the levels of DIMBOA from day 7 to day 9 was identified in BRS Timbaúva and Solstice (12.7 and $11.1 \%$, respectively) and the largest reduction was detected in BRS 327 and PF869120 (46.7 and 46.0\%, respectively). Comparing the HPLC chromatograms obtained for all genotypes (Fig. 2), one different peak was detected in genotype BR 32 at $15.8 \mathrm{~min}$. The peak was observed in 7, 9, and 14 day-old plants but it was less prominent with time (Fig. 3). The fraction corresponding to the peak was subsequently collected and analysed through nuclear magnetic resonance spectroscopy and mass spectrometry. These analyses allowed the identification of the compound as DIMBOA-Glc. The peak corresponding to DIMBOA-Glc (at $15.8 \mathrm{~min}$ ) was found in all other genotypes but always in lower concentration when compared to DIMBOA (at $17.6 \mathrm{~min}$ ). Further NMR using Solstice as $100 \%$. See Table S1 where the means and LSD (5\%) for statistical comparison are displayed, noting that a logtransformation was used here

and MS analysis of the DIMBOA peak purified from BR 32 confirmed that the peak was pure (Supplementary Fig. 14), and not contaminated with other hydroxamic acids e.g. HDMBOA-Glc (Elek et al. 2013a).

\subsection{Aphid development bioassays and correlation with levels of DIMBOA}

For $S$. avenae there was a highly significant effect of genotype for mean number of nymphs per adult alate $(P=0.008, \quad$ F-test $)$, mean growth rate-MGR $(P<0.001$, F-test $)$ and $r_{m}(P=0.001$, F-test $)$. Similarly, for $R$. padi there was a highly significant effect of genotype for mean number of nymphs per adult alate $(P<0.001$, F-test $)$, MGR $(P<0.001$, F-test $)$ and $r_{m}(P=0.015, \mathrm{~F}$-test $)$. The means for the three responses for each aphid species are shown in Table 1 for statistical comparisons to be made. The nymph production after $24 \mathrm{~h}$ was lowest for BRS Guamirim 

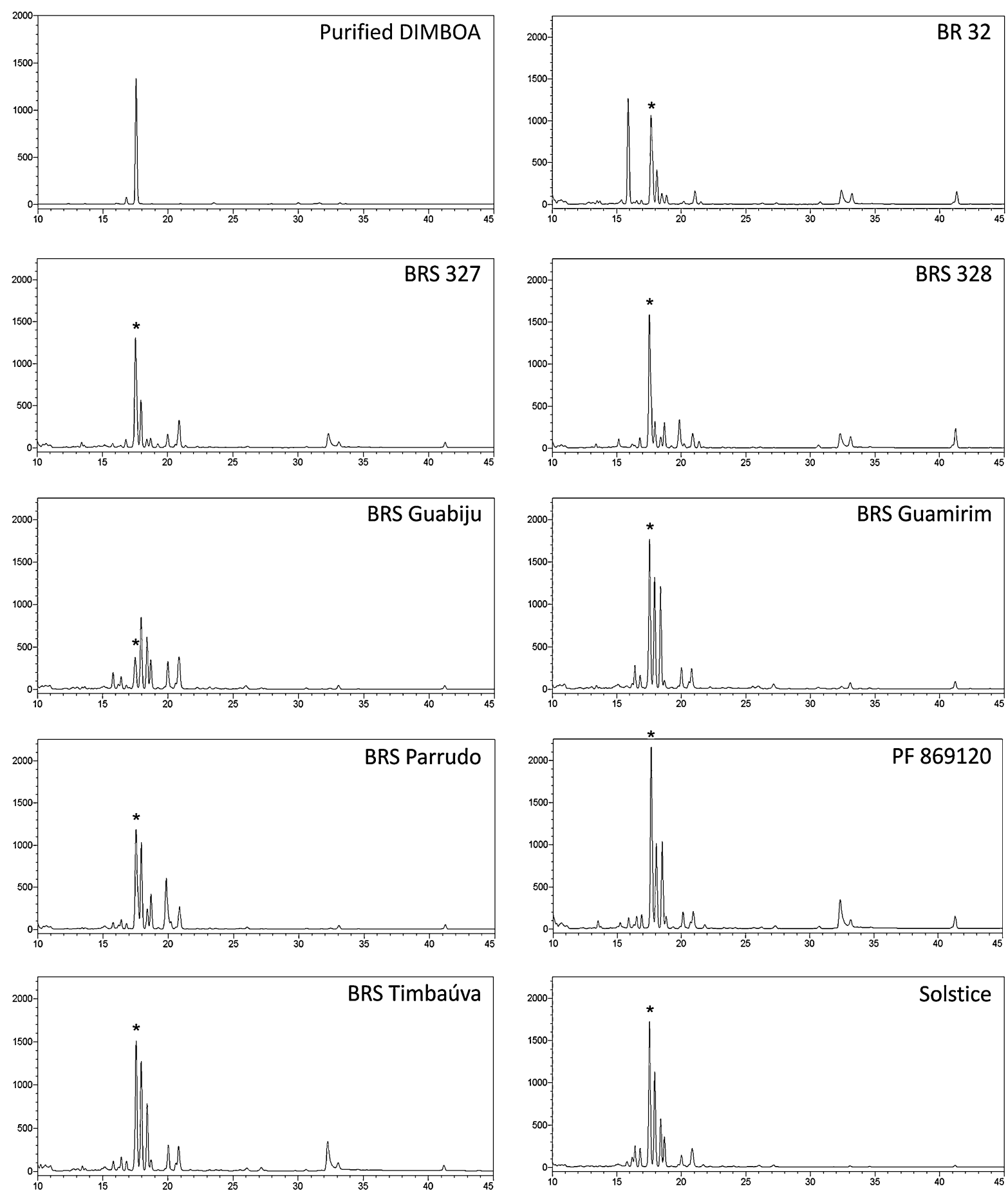

Fig. 2 HPLC chromatograms of 7 days old leaf tissue from the nine genotypes evaluated in this work. Asterisks indicate the peak at $17.6 \mathrm{~min}$ as detected for the purified DIMBOA (top left panel). The $\mathrm{x}$-axis and the $\mathrm{y}$-axis in each chromatogram

represent the time $(\mathrm{min})$ and the absorbance (mAU), respectively. For convenience only the time from 10 to $45 \mathrm{~min}$ is represented 

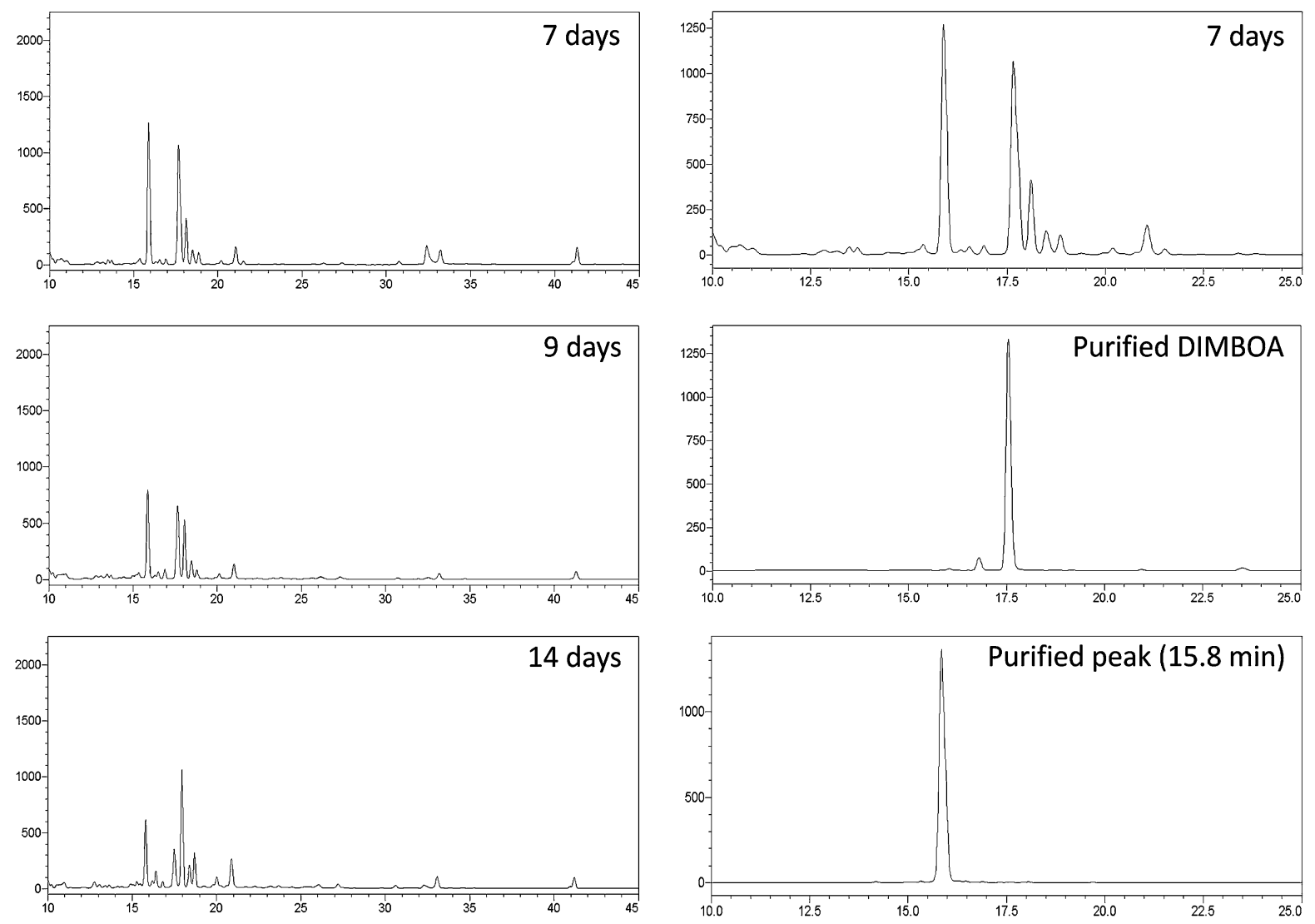

Fig. 3 HPLC chromatograms from the BR 32 genotype. On the left, the chromatograms show the peak at $15.8 \mathrm{~min}$ from 7,9 and 14 days old leaf tissue. On the right, the chromatogram from

7 days old plants, the purified DIMBOA (17.6 min) and the purified peak of interest (15.8 $\mathrm{min}$ ) are shown

and PF869120 for S. avenae and R. padi, respectively (Table 1). However, although both of these genotypes were also among the ones showing best levels of DIMBOA after 7 days (Fig. 1a), other genotypes showing top DIMBOA levels, such as BRS 327, BRS Timbaúva and Solstice, showed a similar nymph production to BRS Guabiju that also showed the lowest level of DIMBOA. Besides that, although $S$. avenae nymph production after $24 \mathrm{~h}$ was least in BRS Guamirim, that genotype performed poorly in terms of the other development measurements (Table 1). Conversely, PF869120 was more consistent in performance over all three measurements. An intermediary MGR for $S$. avenae was detected in BRS Timbaúva while BRS 328 and BR 32 were the ones where a MGR higher than the control Solstice was observed (Fig. 4; Table 1). In general, BRS 327 was the best genotype against $S$. avenae showing the lowest MGR, significantly $(P<0.05$, LSD) different from the rest, and the

lowest intrinsic rate of population increase, though not significantly different $(P<0.05$, LSD) from BRS Timbaúva, BRS Parrudo, Solstice, and PF869120 (Table 1). The four genotypes BRS 327, BRS Timbaúva, BRS Parrudo and PF869120 also presented the lowest intrinsic rate of population increase against $R$. padi and are among the ones showing the best resistance against the bird cherry-oat aphid in other development measurements (Fig. 5). BRS Guabiju showed the worst resistance against $S$. avenae, having the highest intrinsic rate of population increase (Fig. 4c), though not with significant $(P<0.05$, LSD) difference from BRS Guamirim (Table 1). These two genotypes also showed the poorest resistance against $R$. padi (Fig. 5; Table 1).

When considering the three $S$. avenae aphid fecundity responses and the DIMBOA concentrations at 7, 9 and 14 days, no significant $(P<0.05$, F-test $)$ Pearson correlations $(r, n=9)$ were detected 
Table 1 Means for the three fecundity responses for each aphid species

\begin{tabular}{|c|c|c|c|c|c|c|}
\hline \multirow[t]{2}{*}{ Genotype } & \multicolumn{3}{|l|}{ Sitobion avenae } & \multicolumn{3}{|l|}{ Rhopalosiphum padi } \\
\hline & $\begin{array}{l}\text { Mean number of nymphs } \\
\text { per adult alate }\end{array}$ & MGR & $R_{m}$ & $\begin{array}{l}\text { Mean number of nymphs } \\
\text { per adult alate }\end{array}$ & MGR & $R_{m}$ \\
\hline BR 32 & 1.04 & 0.09320 & 0.2910 & 4.30 & 0.0668 & 0.3319 \\
\hline BRS 327 & 1.31 & 0.06037 & 0.2624 & 3.48 & 0.0548 & 0.3061 \\
\hline BRS 328 & 0.95 & 0.08887 & 0.2894 & 2.90 & 0.0616 & 0.3337 \\
\hline BRS Guabiju & 1.24 & 0.08252 & 0.3064 & 3.96 & 0.0599 & 0.3393 \\
\hline BRS Guamirim & 0.93 & 0.08115 & 0.2945 & 4.32 & 0.0599 & 0.3413 \\
\hline BRS Parrudo & 1.18 & 0.07535 & 0.2745 & 3.35 & 0.0557 & 0.3116 \\
\hline PF869120 & 1.11 & 0.08289 & 0.2763 & 2.09 & 0.0581 & 0.3048 \\
\hline BRS Timbaúva & 1.16 & 0.07782 & 0.2668 & 3.70 & 0.0602 & 0.3036 \\
\hline Solstice & 1.08 & 0.07569 & 0.2751 & 4.05 & 0.0648 & 0.3326 \\
\hline SED & 0.120 & 0.00444 & 0.00711 & 0.397 & 0.00304 & 0.01506 \\
\hline Df & 272 & 282 & 290 & 264 & 249 & 266 \\
\hline LSD (5\%) & 0.219 & 0.00875 & 0.01399 & 0.781 & 0.00598 & 0.02964 \\
\hline
\end{tabular}

(Table 2). The only correlation of some interest was the negative one between MGR and DIMBOA concentration at 9 days $(r=-0.607, P=0.083, n=9)$ (Fig. 6; Table 2), with some indication of an increase in DIMBOA concentration being associated with a decrease in the MGR. The full set of Pearson correlations can be seen in a heat map (Fig. 7). There were no significant $(P<0.05$, F-test $)$ correlations $(r$, $n=9$ ) between the three $R$. padi aphid fecundity responses and the DIMBOA concentrations at 7,9 and 14 days (Table 3).

\section{Discussion}

In this work, we investigated the levels of the hydroxamic acid DIMBOA, which is a natural defence compound found in cereals showing detrimental effects against aphids (Züst and Agrawal 2016), in young leaf tissue of wheat genotypes from Brazil. Our goal was to take a step towards achieving a reduced chemical use in Brazilian agriculture and reducing wheat loss due aphid or virus attack. However, even though we were able to detect different levels of DIMBOA and find a variable response against both aphid species (Figs. 1, 4, 5), our results indicate that the levels of DIMBOA in the leaves are not directly correlated with the wheat resistance against two of the most important aphid species in Brazil, S. avenae and $R$. padi. We found that BRS 327 is among the genotypes with the best resistance against both aphid species tested, but showed an intermediary level of DIMBOA, and that BRS Guamirim presented lower resistance than other genotypes, but it showed the second highest level of DIMBOA. Besides that, BRS 328 is among the genotypes showing highest levels of DIMBOA but it is in the bottom group with regard to the resistance against both aphid species.

Hydroxamic acids have been shown to possess negative effects against aphids (Niemeyer 2009; Makowska et al. 2015; Handrick et al. 2016; Züst and Agrawal 2016). A number of previous reports have shown an association between hydroxamic acids and the wheat resistance against aphids. The hydroxamic acid concentrations in six wheat cultivars can explain a higher proportion of the variation in aphid performance (Thackray et al. 1990) and strong correlations between the intrinsic rate of population increase of $S$. avenae and hydroxamic acid levels were also found (Bohidar et al. 1986; Wratten et al. 1988). Highly significant correlations between $S$. avenae preference and DIMBOA levels in the seedlings of a worldwide range of 47 cultivars of Triticum were also found by Nicol et al. (1992). Higher DIMBOA concentration in flag leaves in comparison to ears at anthesis was consistent with the higher MRGR of $S$. avenae in ears than in flag leaves (Nicol and Wratten 1997). Besides that, the susceptibility of three grass species to Metopolophium dirhodum is related to the presence or absence of those 

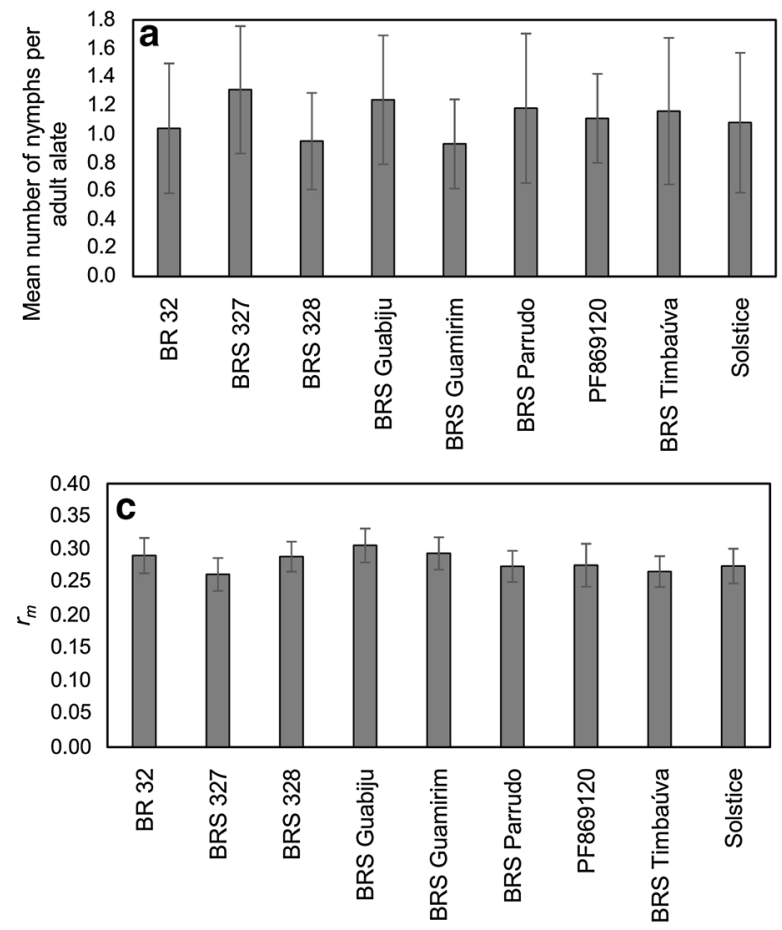

Fig. 4 Development measurements of the S. avenae aphids on the nine wheat genotypes analysed in this work. Results are shown for a mean number of nymphs produced per alate adult after $24 \mathrm{~h}$, b mean growth rate (MGR), c intrinsic rate of

acids (Argandoña et al. 1980), DIMBOA was shown to deter feeding by $R$. padi and to reduce BYDV transmission to wheat (Givovich and Niemeyer 1991) and effects of hydroxamic acids in aphid performance was also reported by others (Niemeyer et al. 1989; Givovich and Niemeyer 1994; Givovich et al. 1994; Bravo and Copaja 2002). When considering only BRS Timbaúva and BRS Guabiju, two of the wheat genotypes evaluated here, it is clear that an association exist between the DIMBOA and the plant resistance against $S$. avenae and $R$. padi. This is because BRS Timbaúva showed one of the highest levels of DIMBOA and also one of the best resistances against both aphid species while BRS Guabiju showed the lowest level of DIMBOA and it is among the genotypes with the lowest resistances against both aphids (Figs. 1, 4, 5). Although this is the first time that hydroxamic acids levels are evaluated in Brazilian wheat, those two cultivars (BRS Timbaúva and BRS Guabiju) are commonly studied in Brazil for aphid resistance. Our data related to the plant resistance (Figs. 4, 5) is in agreement with the data from the
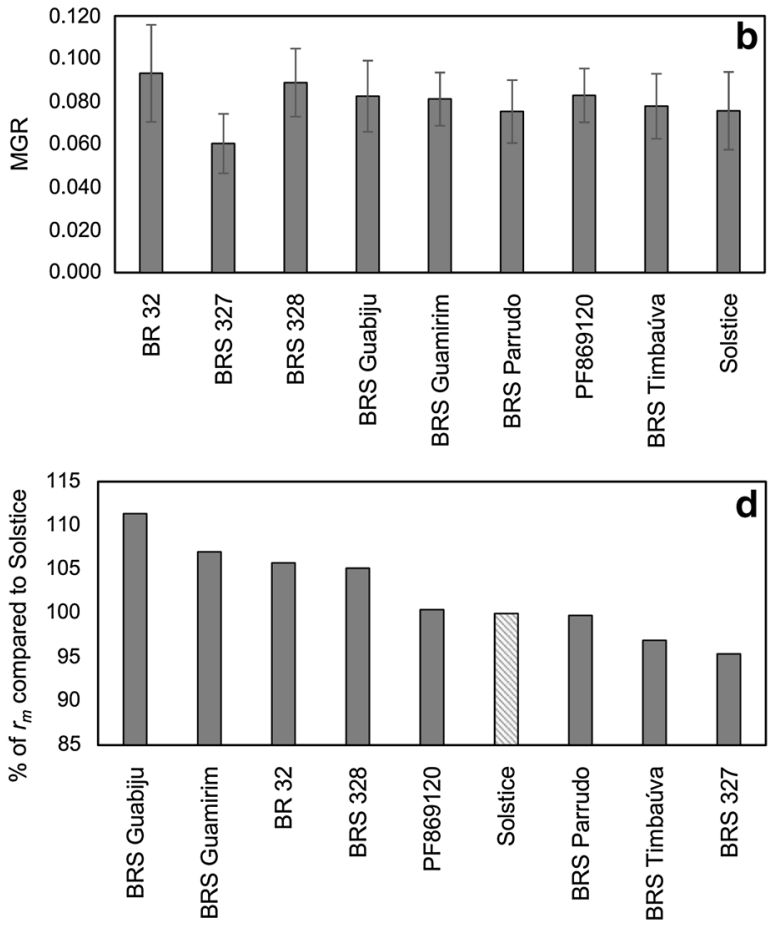

population increase $\left(r_{m}\right)$, and $\mathbf{d}$ percentage of the intrinsic rate of population increase using Solstice as $100 \%$. See Table 1 where the means and LSD (5\%) for statistical comparison are displayed

literature where the cultivar BRS Timbaúva has shown a lower reduction in grain production after infection with $R$. padi, while BRS Guabiju is among the ones with highest reduction in productivity (Peruzzo et al. 2007; Cezare et al. 2011; Savaris et al. 2013). Besides that, the resistance of BRS Timbaúva and BRS Guabiju to $R$. padi detected by others can be correlated to the antibiosis data showed here. Antibiosis happens when insects feed from a particular plant but an adverse effect occurs on their biology reducing their growth or survival (Berzonsky et al. 2003). In this work, BRS Timbaúva was among the genotypes showing lower intrinsic rate of population increase (average of $30.57 \%$ ) while BRS Guabiju presented the highest rate (average of $33.97 \%$ ) (Fig. 5c) meaning that the $R$. padi population will increase, on average, $3.40 \%$ more per unit of time (in this case one day) in BRS Guabiju than in BRS Timbaúva, which could result in higher damage and higher losses in grain production. In this case, an antibiosis-type effect (slower growth of $R$. padi) could be linked to a tolerance-type effect (low reduction in grain 

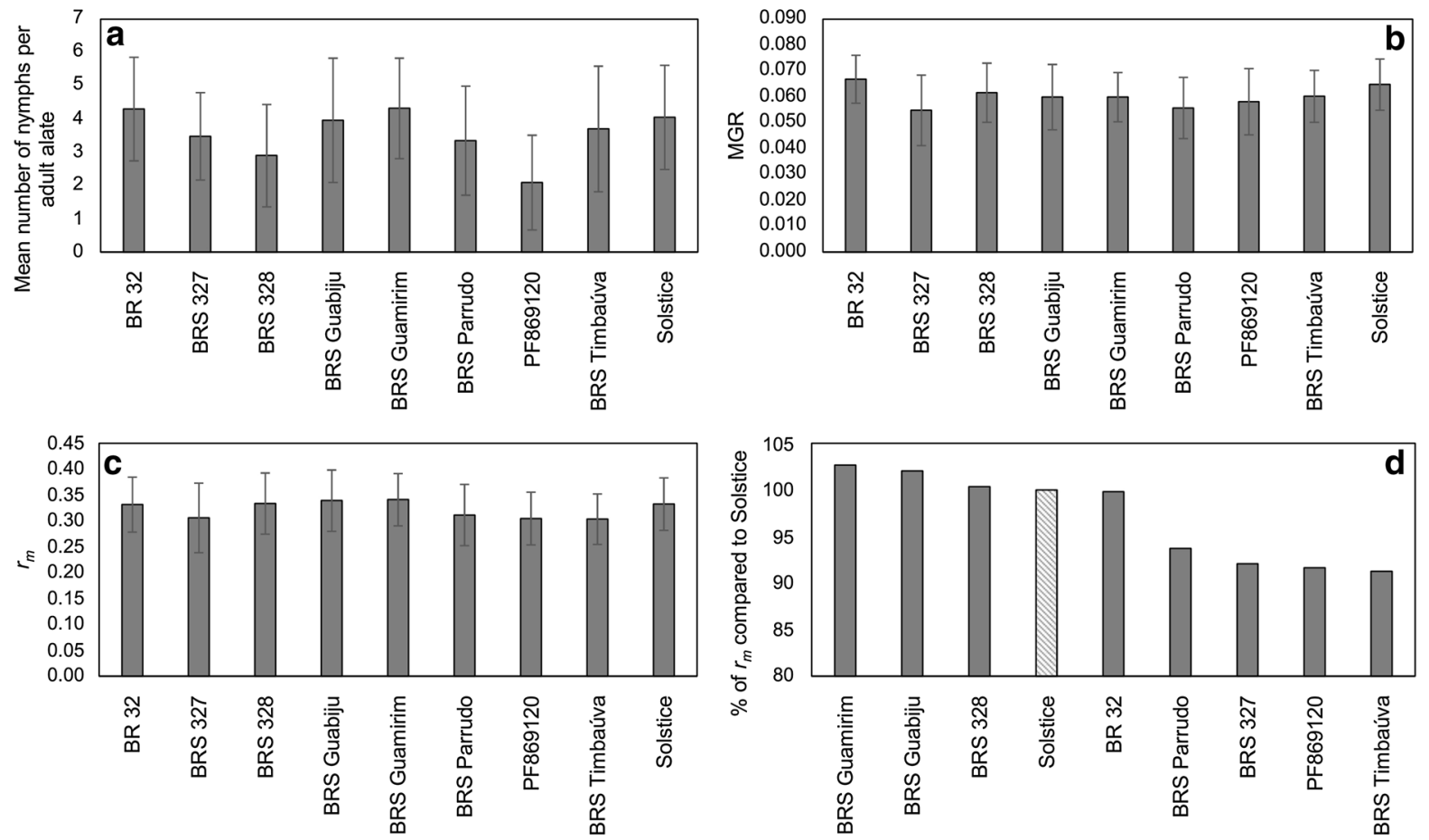

Fig. 5 Development measurements of the R. padi aphids on the nine wheat genotypes analysed in this work. Results are shown for a mean number of nymphs produced per alate adult after $24 \mathrm{~h}$, b mean growth rate (MGR), c intrinsic rate of population

increase $\left(r_{m}\right)$, and $\mathbf{d}$ percentage of the intrinsic rate of population increase using Solstice as $100 \%$. See Table 1 where the means and LSD (5\%) for statistical comparison are displayed

Table 2 Pearson correlations between the three $S$. avenae aphid fecundity responses and the DIMBOA concentrations at 7, 9 and 14 days

\begin{tabular}{llllll}
\hline & $\begin{array}{l}\text { Mean number of nymphs } \\
\text { per adult alate }\end{array}$ & $P$-value & MGR & $P$-value & $R_{m}$ \\
\hline DIMBOA 7 days & -0.381 & 0.311 & -0.054 & 0.890 & -0.257 \\
DIMBOA 9 days & -0.065 & 0.868 & -0.607 & 0.083 & -0.518 \\
DIMBOA 14 days & -0.206 & 0.595 & -0.380 & 0.313 & -0.495 \\
\hline
\end{tabular}

Fig. 6 Scatter plot of pairs of mean values per genotype for Sitobion avenae MGR and corresponding DIMBOA concentration at 9 days. See Table 2 for the Pearson correlation and $P$ value

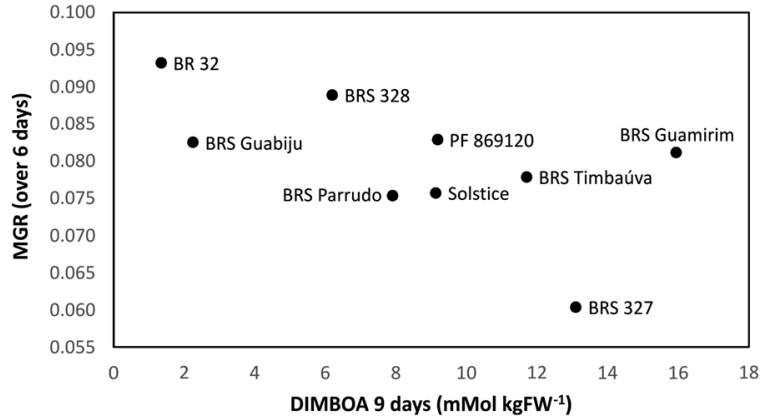




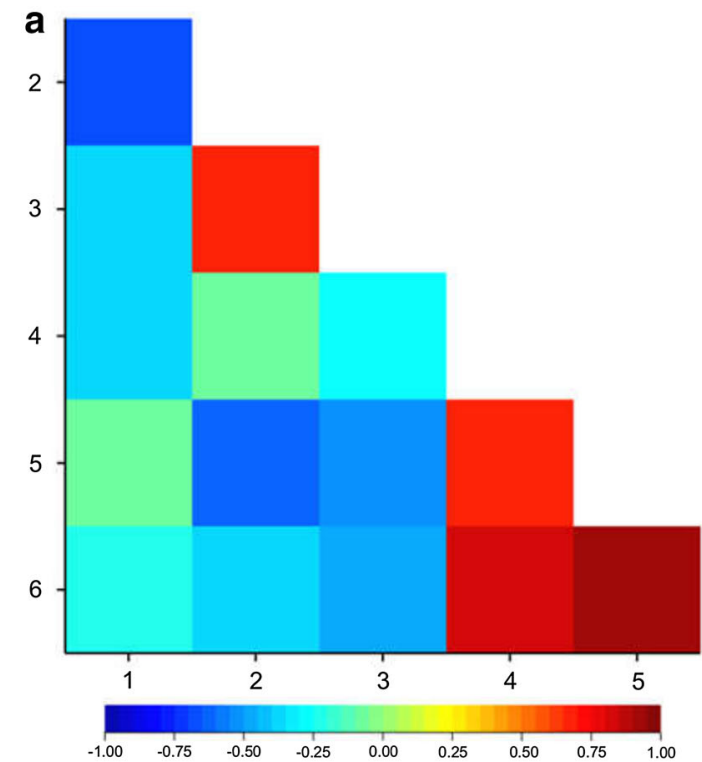

Fig. 7 Heat map of the Pearson correlations between DIMBOA concentrations, in nine wheat genotypes at three time points, and aphid fecundity responses for $\mathbf{a} S$. avenae and $\mathbf{b} R$. padi. The key

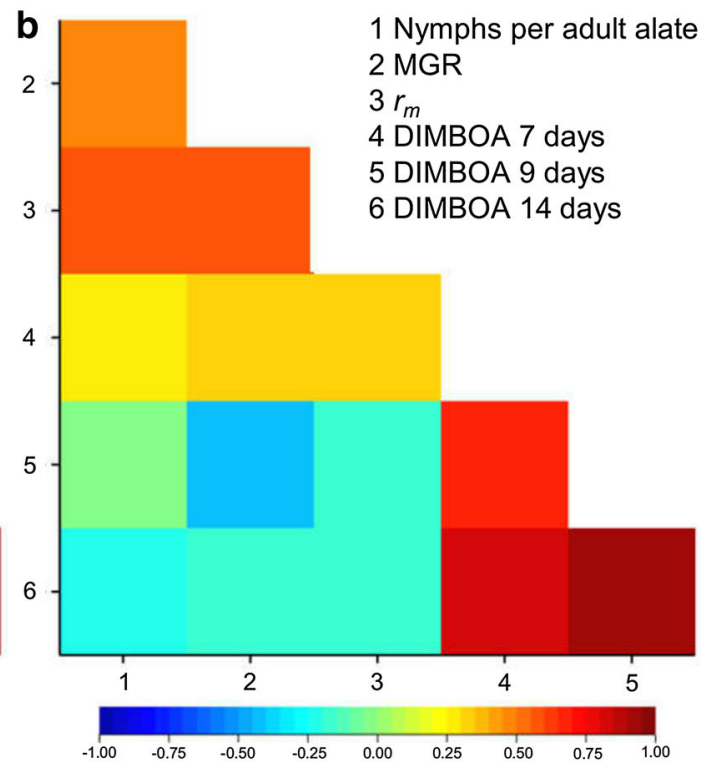

is to show the pairs of responses and scale to show the correlations by colour trend (from -1 to +1 )

Table 3 Pearson correlations between the three $R$. padi aphid fecundity responses and the DIMBOA concentrations at 7, 9 and 14 days

\begin{tabular}{llllrrr}
\hline & $\begin{array}{l}\text { Mean number of nymphs } \\
\text { per adult alate }\end{array}$ & $P$-value & MGR & $P$-value & $R_{m}$ & $P$-value \\
\hline DIMBOA 7 days & 0.270 & 0.482 & 0.346 & 0.361 & 0.325 \\
DIMBOA 9 days & -0.007 & 0.985 & -0.400 & 0.286 & -0.196 & 0.614 \\
DIMBOA 14 days & -0.201 & 0.604 & -0.176 & 0.652 & -0.176 & 0.650 \\
\hline
\end{tabular}

production) in the cultivar BRS Timbaúva. This same result, a lower population growth of $R$. padi and lower reduction in grain number for BRS Timbaúva when compared to BRS Guabiju, was also observed by Savaris et al. (2013). Here, BRS Timbaúva was also one of the genotypes showing best resistance against $S$. avenae (Fig. 4). Interestingly, Silva et al. (2013) described BRS Timbaúva as susceptible (by antibiosis) to $S$. avenae showing higher $r_{m}$ in leaves and ears when compared to other wheat genotypes. However, it is important to point out that these authors assessed the $r_{m}$ using a methodology different from the one used here. Besides that, we used aphids collected in UK fields and the genetic variability between populations from UK and Brazil could result in different plant resistances.

There are a few reports about the lack of correlation between hydroxamic acid levels and wheat resistance against aphids. For instance, hydroxamic acids showed no correlation with a variable response to $R$. padi fecundity of five wheat varieties (representing UK and Iranian origin and tetra and hexaploid what) at tillering stage (Kazemi and Emden 1992). Additionally, levels of hydroxamic acids in tetra- and hexaploid wheat did not correlate with $R$. padi settlement and reproduction (Elek et al. 2013a). The explanation for the lack of correlation between levels of DIMBOA and plant resistance, as detected in our study, could be that (i) levels of hydroxamic acids produced by the wheat genotypes were too low to cause an effect, (ii) there is lack of contact between the aphid and the hydroxamic acid, (iii) aphids are able to detoxify or avoid the detrimental effects of the hydroxamic acids, (iv) aphid have adapted to the signal, and (v) the observed resistance in Brazilian genotypes is due to secondary metabolites other than hydroxamic acids or is due to 
other hydroxamic acids. The quantity of hydroxamic acid detected in hexaploid wheat, as in the genotypes evaluated in this paper, is considerably lower when compared to diploid or tetraploid wheat plants (Gordon-Weeks et al. 2010; Elek et al. 2013a, b, 2014). Five-times more DIMBOA was found in Aegilops speltoides (B genome) when compared to Solstice (hexaploid wheat), and tetraploid wheat genotypes show twice more DIMBOA-Glc than hexaploid varieties (Gordon-Weeks et al. 2010; Elek et al. 2013a). Even so, the higher levels recorded in the tetraploid varieties were not able to deter aphid settlement or reduce fecundity (Elek et al. 2013a) but, in contrast, the high level detected in diploid wheat had a significant impact on S. avenae development (Gordon-Weeks et al. 2010). Moreover, Aegilops speltoides, a diploid ancestor of wheat, showed very high levels of hydroxamic acids and substantially low nymph production for $R$. padi (Elek et al. 2014). In this way, in genotypes where the hydroxamic acid concentration is high, the aphids could reach the phloem avoiding them and/or before encountering sufficient toxic levels (Givovich et al. 1994; Elek et al. 2014) and, in genotypes as the ones reported here, the lack of correlation could be a matter of low levels of DIMBOA. Thus, the assessment of hydroxamic acids in diploid and tetraploid wheat where a significant reduction in aphid development is imposed could offer an alternative to improve their levels in hexaploid wheat either by understanding their regulation or by producing synthetic wheat lines. Considering the aphids' ability to detoxify or avoid the hydroxamic acids, up to now, only DIMBOA-Glc, which is less efficient than the unglucosylated form, was detected in the phloem sap of hexaploid wheat (Givovich et al. 1994). It has been theorized that aphid avoidance of compartmentalized hydroxamic acids could be an alternative strategy of aphids to overcome their toxic effects (Molyneux et al. 1990). In this context, the correlation between DIMBOA concentration in the leaf and the phloem sap should be taken into account. For instance, large and clear differences in the whole leaf hydroxamic acid content were detected in three wheat cultivars but the DIMBOA-Glc concentrations in the phloem sap were similar among them (Givovich et al. 1994). New studies will be needed to evaluate if an increased DIMBOA concentration in the leaves of Brazilian wheat will be associated with a higher level located in the phloem sap. Besides that, increase in enzymatic activity has been detected in aphids growing in wheat containing different amounts of hydroxamic acids. These enzymes could act on the hydroxamic acids leading to compounds more readily excretable by aphids, meaning that some aphids are able to detoxify the harmful compounds and thus gain an advantage over competitors (Loayza-Muro et al. 2000; Maag et al. 2014). This would mean that small increments in the concentration of hydroxamic acids in wheat would not be beneficial. Moreover, adaptation to higher levels of hydroxamic acids could evolve in aphids since they can produce several generations in a short period of time. For instance, a new biotype of the Russian wheat aphid, Diuraphis noxia, was able to break down the resistance of wheat varieties released previously (Castro et al. 2005) and, for other plant species too, some resistance-breaking aphid biotypes have been discovered (Dogimont et al. 2010). Plants showing different concentrations of hydroxamic acids were able to generate genotypic differences in $S$. avenae after just a few generations (Figueroa et al. 2002) and the assessment of the genetic variability and population structure of $S$. avenae, collected in Chile, has revealed that some aphid genotypes show highest performance on plants with the highest concentration of hydroxamic acids. It was therefore predicted that, through time, these hydroxamic acid-resistant clones would begin to prevail (Figueroa et al. 2004). Even morphological characters, such as the presence or absence of wings, that could result from environmental stress, could have an effect on aphid performance on plants with different levels of hydroxamic acids (Castañeda et al. 2010). In this way, bioassays performed with aphids collected recently could give different results to those in the past, especially if collected from fields in different countries. Finally, recent studies on aphid resistance in maize have shown that natural variation in aphid resistance is associated with 2,4-dihydroxy-7-methoxy-1,4-benzoxazinone glucoside methyltransferase activity (Meihls et al. 2013) and 8-O-methylated benzoxazinoids (Handrick et al. 2016), suggesting that DIMBOA may not be the active principle in wheat for secondary-metabolite based aphid resistance.

To conclude, measurement of DIMBOA levels in young leaves of Brazilian wheat genotypes was reported, and resistance of the genotypes against two of the most important aphid species in Brazil was evaluated. There was variation in the DIMBOA levels 
among the genotypes and in their resistance against $S$. avenae and $R$. padi, but there was no clear correlation between the levels of DIMBOA and antibiosis. Future studies should consider if the level of DIMBOA found in leaf samples correlate with the concentration specifically measured in the phloem sap. The tolerance of BRS Timbaúva described by others could be partially explained by the low intrinsic growth rate detected in both aphid species. Besides that, BRS Timbaúva had the highest DIMBOA concentration at 7 days, but, adversely, it also had the highest decrease of DIMBOA levels between the 7th and 14th days. Further work is required to elucidate the secondary metabolite basis of resistance in the genotypes tested, which, by using methods such as genetic engineering, exploring accessions in germplasm banks and synthetic wheat, increments in the concentration of metabolites should be possible, in order to combat increases in aphid resistance in hexaploid wheat. For this, a larger number of plant genotypes may need to screened, and so it is important to consider the development of a reliable high-throughput assay for screening aphid development.

Acknowledgements We are thankful for the financial support of Rothamsted International Fellowship Scheme, Conselho Nacional de Desenvolvimento Científico e Tecnológico (CNPq) - process number 211732/2013-3, Embrapa (Empresa Brasileira de Pesquisa Agropecuária) and Biotechnology and Biological Sciences Research Council (BBSRC) of the United Kingdom (BB/L02652X/1). We also thank Dr Keith Chamberlain from Rothamsted Research for helping with the HPLC analysis and Dr Douglas Lau from Embrapa Trigo for helpful discussions.

\section{References}

Ahmad S, Veyrat N, Gordon-Weeks R, Zhang Y, Martin J, Smart L, Glauser G, Erb M, Flors V, Frey M, Ton J (2011) Benzoxazinoid metabolites regulate innate immunity against aphids and fungi in maize. Plant Physiol 157:317-327

Argandoña VH, Luza LC, Niemeyer HM, Corcuera LJ (1980) Role of hydroxamic acids in the resistance of cereals to aphids. Phytochemistry 19:1665-1668

Baumeler A, Hesse M, Werner C (2000) Benzoxazinoids-cyclic hydroxamic acids, lactams and their corresponding glucosides in the genus Aphelandra (Acanthaceae). Phytochemistry 53:213-222

BCC Research (2017) Global markets for biopesticides. Report Code CHM029F
Berzonsky WA, Ding H, Haley SD, Lamb RJ, McKenzie RIH, Ohm HW, Patterson FL, Peairs FB, Porter DR, Ratcliffe RH, Shanower TG (2003) Breeding wheat for resistance to insects. Plant Breed Rev 22:221-296

Bohidar K, Wratten SD, Niemeyer HM (1986) Effects of hydroxamic acids on the resistance of wheat to the aphid Sitobion avenae. Ann App Biol 109:193-198

Bravo HR, Copaja SV (2002) Contents and morphological distribution of 2,4-dihydroxy-1,4-benzoxazin-3-one and 2-benzoxazolinone in Acanthus mollis in relation to protection from larvae of Pseudaletia impuncta. Ann Appl Biol 140:129-132

Cao HH, Pan MZ, Liu HR, Wang SH, Liu TX (2015) Antibiosis and tolerance but not antixenosis to the grain aphid, Sitobion avenae (Hemiptera:Aphididae), are essential mechanisms of resistance in a wheat cultivar. Bull Entomol Res 105:448-455

Castañeda LE, Figueroa CC, Bacigalupe LD, Nespolo RF (2010) Effects of wing polyphenism, aphid genotype and host plant chemistry on energy metabolism of the grain aphid, Sitobion avenae. J Insect Physiol 56:1920-1924

Castro AM, Vasicek A, Manifiesto M, Giménez O, Tacaliti MS, Dobrovolskaya O, Röder MS, Snape JW, Börner A (2005) Mapping antixenosis genes on chromosome $6 \mathrm{~A}$ of wheat to greenbug and to a new biotype of Russian wheat aphid. Plant Breed 124:229-233

Cezare DG, Schons J, Lau D (2011) Análise da resistência/tolerância da cultivar de trigo BRS Timbaúva ao Barley yellow dwarf virus: PAV. Trop Plant Pathol 36:249-255

Dogimont C, Bendahmane A, Chovelon V, Boissot N (2010) Host plant resistance to aphids in cultivated crops: genetic and molecular bases, and interactions with aphid populations. CR Biol 333:566-573

Elek H, Smart L, Martin J, Ahmad S, Gordon-Weeks R, Welham S, Nádasy M, Pickett JA, Werner CP (2013a) The potential of hydroxamic acids in tetraploid and hexaploid wheat varieties as resistance factors against the bird-cherry oat aphid, Rhopalosiphum padi. Ann Appl Biol 162:100-109

Elek H, Smart L, Martin J, Ahmad S, Gordon-Weeks R, Anda A, Welham S, Werner P, Pickett J (2013b) Hydroxamic acids in Aegilops species and effects on Rhopalosiphum padi behaviour and fecundity. Bull Insectol 66:213-220

Elek H, Smart L, Ahmad S, Anda A, Werner C, Pickett J (2014) A comparison of the levels of hydroxamic acids in Aegilops speltoides and a hexaploid wheat and effects on Rhopalosiphum padi behaviour and fecundity. Acta Biol Hung 65:38-46

Figueroa CC, Loayza-Muro R, Niemeyer HM (2002) Temporal variation of RAPD-PCR phenotype composition of the grain aphid Sitobion avenae (Hemiptera:Aphididae) on wheat: the role of hydroxamic acids. Bull Entomol Res 92:25-33

Figueroa CC, Simon J, Gallic J, Prunier-Leterme N, Briones LM, Dedryver C, Niemeyer HM (2004) Effect of host defense chemicals on clonal distribution and performance of different genotypes of the cereal aphid Sitobion avenae. J Chem Ecol 30:2515-2525

Givovich A, Niemeyer HM (1991) Hydroxamic acids affecting barley yellow dwarf virus transmission by the aphid Rhopalosiphum padi. Entomol Exp Appl 59:79-85 
Givovich A, Niemeyer HM (1994) Effect of hydroxamic acids on feeding behavior and performance of cereal aphids on wheat. Eur J Entomol 91:371-374

Givovich A, Sandström J, Niemeyer HM, Pettersson J (1994) Presence of a hydroxamic acid glucoside in wheat phloem sap, and its consequences for the performance of Rhopalosiphum padi (L.) (Homoptera:aphididae). J Chem Ecol 20:1923-1930

Gordon-Weeks R, Smart L, Ahmad S, Elek H, Zhang Y, Martin J, Pickett J (2010) The regulation of a natural plant defence pathway in wheat and its role in aphid resistance. Biology of plant-microbe interactions. In: Proceedings of the 14th International congress on molecular plant-microbe interactions. Quebec City, Quebec, Canada

Grube A, Donaldson D, Kiely T, Wu L (2011) Pesticides industry sales and usage-2006 and 2007 market estimates. United States Environmental Protection Agency, Washington, p 33

Handrick V, Robert CA, Ahern KR, Zhou S, Machado RA, Maag D, Glauser G, Fernandez-Penny FE, Chandran JN, Rodgers-Melnik E, Schneider B, Buckler ES, Boland W, Gershenzon J, Jander G, Erb M, Köllner TG (2016) Biosynthesis of 8-O-methylated benzoxazinoid defense compounds in maize. Plant Cell 28:1682-1700

Kazemi MH, Emden HV (1992) Partial antibiosis to Rhopalosiphum padi in wheat and some phytochemical correlations. Ann Appl Biol 121:1-9

Lanzarini AC, Schons J, Salvadori JR, Nienow AA, NicoliniTeixeira F, Binotto-Missiura F, Deuner E (2007) Avaliação de danos causados pelo Barley yellow dwarf virus: PAV em cultivares de trigo no Brasil. Fitopatol Bras 32:512-517

Lau D, Pereira PRVS, Castro RL (2015) Ensaio estadual de cultivares de trigo do Rio Grande do Sul 2014 — reação ao mosaico comum. In: Reunião da Comissão Brasileira de Pesquisa de Trigo e Triticale 2015, Passo Fundo. Anais... Biotrigo Genética, Passo Fundo

Lau D, Pereira PRVS, Salvadori JR, Schons J, Parizoto G, Mar TB (2009) Ocorrência do Barley/Cereal yellow dwarf virus e seus vetores em cereais de inverno no Rio Grande do Sul, Santa Catarina, Paraná e Mato Grosso do Sul em 2008. Embrapa Trigo, Passo Fundo, p 10

Loayza-Muro R, Figueroa CC, Niemeyer HM (2000) Effect of two wheat cultivars differing in hydroxamic acid concentration on detoxification metabolism in the aphid Sitobion avenae. J Chem Ecol 26:2725-2736

Maag D, Dalvit C, Thevenet D, Köhler A, Wouters FC, Vassão DG, Gershenzon J, Wolfender JL, Turlings TCJ, Erb M, Glauser G (2014) 3- $\beta$-D-Glucopyranosyl-6-methoxy-2benzoxazolinone (MBOA- $N$-Glc) is an insect detoxification product of maize 1,4-benzoxazin-3-ones. Phytochemistry 102:97-105

Makowska B, Bakera B, Rakoczy-Trojanowska M (2015) The genetic background of benzoxazinoid biosynthesis in cereals. Acta Physiol Plant 37:176

Meihls LN, Handrick V, Glauser G, Barbier H, Kaur H, Haribal MM, Lipka AE, Gershenzon J, Buckler ES, Erb M, Köllner TG, Jander G (2013) Natural variation in maize aphid resistance is associated with 2,4-dihydroxy-7-methoxy1,4-benzoxazin-3-one glucoside methyltransferase activity. Plant Cell 25:2341-2355
Molyneux RJ, Campbell BC, Dreyer DL (1990) Honeydew analysis for detecting phloem transport of plant natural products. Implications for host-plant resistance to sapsucking insects. J Chem Ecol 16:1899-1909

Nicol D, Wratten SD (1997) The effect of hydroxamic acid concentration at late growth stages of wheat on the performance of the aphid Sitobion avenae. Ann Appl Biol 130:387-396

Nicol D, Copaja SV, Wratten SD, Niemeyer HM (1992) A screen of worldwide wheat cultivars for hydroxamic acid levels and aphid antixenosis. Ann Appl Biol 121:11-18

Niemeyer HM (2009) Hydroxamic acids derived from 2-hydroxy-2H-1,4-benzoxazin-3(4H)-one: key defense chemicals of cereals. J Agric Food Chem 57:1677-1696

Niemeyer HM, Pesel E, Copaja SV, Bravo HR, Franke S, Francke W (1989) Changes in hydroxamic acid levels of wheat plants induced by aphid feeding. Phytochemistry 28:447-449

Parizoto G, Rebonatto A, Schons J, Lau D (2013) Barley yellow dwarf virus-PAV in Brazil: seasonal fluctuation and biological characteristics. Trop Plant Pathol 38:11-19

Pereira PRSV, Salvadori JR, Lau D (2010) Cereais de inverno: principais insetos-praga. In: Santos HP et al (eds) Sistemas de produção para cereais de inverno sob plantio direto no sul do Brasil. Embrapa Trigo, Passo Fundo, pp 225-254

Peruzzo R, Salvadori JR, Pereira PRVS, Bertollo EC, Tonello LS (2007) Resposta de cultivares de trigo à infestação do pulgão Rhopalosiphum padi. Pesq Agropec Bras 42:1681-1685

Savaris M, Lampert S, Salvadori JR, Lau D, Pereira PRVS, Smaniotto MA (2013) Population growth and damage caused by Rhopalosiphum padi (L.) (Hemiptera, Aphididae) on different cultivars and phonological stages of wheat. Neotrop Entomol 42:539-543

Silva AM, Sampaio MV, de Oliveira RS, Korndorfer AP, Ferreira SE, Polastro GC, Dias PAS (2013) Antibiosis and non-preference of Sitobion avenae (F.) (Hemiptera:Aphididae) on leaves and ears of commercial cultivars of wheat (Triticum aestivum). Neotrop Entomol 42:304-310

Thackray DJ, Wratten SD, Edwards PJ, Niemeyer HM (1990) Resistance to the aphids Sitobion avenae and Rhopalosiphum padi in graminae in relation to hydroxamic acid levels. Ann Appl Biol 116:573-582

Whalon ME, Mota-Sanchez D, Hollingworth RM, Duynslager L (2017) Arthropod pesticide resistance data base. http:// www.pesticideresistance.com/. Accessed 25 March 2017

Wouters FC, Gershenzon J, Vassão DG (2016) Benzoxazinoids: reactivity and modes of action of a versatile class of plant chemical defenses. J Braz Chem Soc 27:1379-1397

Wratten SD, Thackray DJ, Edwards PJ, Niemeyer HM (1988) Effects of hydroxamic acids on the resistance of wheat to the aphid Sitobion avenae. In: Cavalloro R, Sunderland KD (eds) Integrated crop protection in cereals. AA Balkema, Rotterdam, pp 57-60

Wyatt JI, White FP (1977) Simple estimation of intrinsicrates for aphids and tetranychid mites. J Appl Ecol 14:757-766

Züst T, Agrawal AA (2016) Mechanisms and evolution of plant resistance to aphids. Nat Plants 2:15206 